\title{
Job loss and the mental health of spouses and adolescent children
}

\author{
Melisa Bubonya', Deborah A. Cobb-Clark ${ }^{2,3,4}$ and Mark Wooden ${ }^{1,4^{*}}$ (D)
}

\author{
* Correspondence: \\ m.wooden@unimelb.edu.au \\ ${ }^{1}$ Melbourne Institute of Applied \\ Economic and Social Research, \\ University of Melbourne, L5 FBE \\ Bldg, 111 Barry St, Melbourne, \\ Victoria 3010, Australia \\ ${ }^{4}$ Institute of Labor Economics (IZA), \\ Melbourne, Australia \\ Full list of author information is \\ available at the end of the article
}

\begin{abstract}
Panel data from the Household, Income and Labour Dynamics in Australia Survey are used to examine the impact of involuntary job loss on the mental health of spouses and adolescent children. Estimates from fixed effects models show that the mental health of women (but not men) declines following a spouse's job loss, but only if that job loss results in a sustained period of non-employment or if the couple experienced prior financial hardship or relationship strain. A negative effect of parental job loss on the mental health of adolescent children is also found but is restricted to girls.

JEL Classification: I31, J10, J65
\end{abstract}

Keywords: Unemployment, Involuntary job loss, Mental health, Families, Spouses, Adolescents, HILDA Survey

\section{Introduction}

Mental illness is a public health problem with substantial economic costs. The Organisation for Economic Co-operation and Development (OECD), for example, reports that the economic cost of mental health problems in some developed countries is estimated to range between 2.3 and 4.4\% of gross national product (OECD 2014). Much of this cost stems from reduced employment levels, increased absenteeism, and lost productivity among those with poor mental health (Fletcher 2013; Layard 2013). At the same time, labour markets play a major role in driving mental health outcomes. Mental health deteriorates when labour market conditions worsen (Melnychuk 2012; Gili et al. 2013), and differences in labour market institutions explain part of the crosscountry disparity in the incidence of psychological distress among workers (Cottini and Lucifora 2013). Most importantly, there is a vast research literature linking unemployment to diminished mental health for workers (for reviews, see Feather 1990; Dooley et al. 1996; Kasl et al. 1998; Paul and Moser 2009).

Despite the importance of the issue, and the voluminous literature, the OECD concluded in its recent review that the "available evidence on mental illness and its connection with work is partial or incomplete, and many important elements are still unknown or not fully understood" (OECD 2012, p. 200). In particular, although it is widely accepted that there are likely to be spillover effects of job loss on the mental health of the family members of job losers (Ström 2003), empirical evidence on these intra-household effects remains scarce.

(c) The Author(s). 2017 Open Access This article is distributed under the terms of the Creative Commons Attribution 4.0 International License (http://creativecommons.org/licenses/by/4.0/), which permits unrestricted use, distribution, and reproduction in any medium, provided you give appropriate credit to the original author(s) and the source, provide a link to the Creative Commons license, and indicate if changes were made. 
The objective of this paper is to fill this void in the literature by using nationally representative household panel data to assess the implications of involuntary job loss for the mental health of family members. We make an important contribution in focusing specifically on the disparity in mental health outcomes following job loss in those families experiencing (i) continued non-employment, (ii) financial stress, and (iii) relationship dissatisfaction. Although we do not estimate mediating effects directly, this focus on heterogeneity in mental health impacts sheds light on the potential pathways through which job loss affects family members. Further, while there is a small literature on the link between partners' job loss and their spouses' mental health, ours is the first study to also analyse the broader impact of men's and women's job loss on the mental health of their adolescent and young-adult children. Finally, we employ fixed effects models rich in controls in order to account for any selection on observable or timeinvariant unobservable individual or family characteristics. We deal with any remaining concerns about the potential endogeneity of job loss by utilising a measure of involuntary job loss, which we argue has certain advantages over other job loss measures used previously in the literature. The robustness of our findings is then tested using an alternative measure of job loss that is both unexpected and involuntary. Together, these innovations allow us to add estimates that are more plausibly causal to what is largely a correlational literature.

Developing sensible policies to reduce the economic and social burden of mental illness requires knowing more about the impact poor labour market outcomes have on families. Our results provide evidence that, in some cases, there are sizeable spillover effects of husbands' job loss on the mental health of their wives and of mothers' job loss on their young-adult daughters, implying that previous studies that do not address this underestimate the public health costs of job loss. In particular, we estimate that the chances of a woman experiencing severe depressive symptoms after their husband's job loss is approximately two-thirds greater if the family is already experiencing cash flow problems than if it is not. Similarly, the incidence of depressive symptoms for adolescents whose mothers lose their jobs is more than two-thirds higher for girls relative to boys and for those whose mothers are not reemployed quickly. ${ }^{1}$ The existence of these spillover effects suggests that it may be cost-effective for policy initiatives to take a family perspective when addressing job loss. That said, when averaged across all families, the estimated effects of job loss on the mental health of other family members mostly seem very small, suggesting that existing estimates of the total economic cost of mental health problems may not be greatly understated.

\section{Previous research}

It is well established that the onset of unemployment is inversely correlated with indicators of psychological well-being and mental health, with one meta-analysis supporting the hypothesis that the relationship between job loss and mental health is causal (Paul and Moser 2009). ${ }^{2}$ At the same time, it has long been recognised that unemployment is a significant event not just for those directly experiencing it but also for their family members (e.g., Komarovsky 1940). Furthermore, there may be spillovers between the mental health states of family members (Fletcher 2009; Mervin and Frijters 2014). As a result, we might expect the onset of unemployment to be associated with 
deterioration in the psychological well-being not only of the job loser but of other family members as well.

Most research on this issue has focused on spousal well-being, typically presenting evidence that husbands' job loss is negatively associated with the psychological wellbeing of their wives. This relationship is perhaps not surprising given that traditional social norms emphasise men's role in providing economic resources for their families (Nock 1998; Townsend 2002) and wives' marital satisfaction is often higher when their husbands take a lead in breadwinning (Wilcox and Nock 2007). Still, gender roles are changing and women's earnings now constitute an increasing share of the household budget (Raley et al. 2006). Men and women also perceive their families' financial situations very differently (Zagorsky 2003). For both reasons, it is important to explicitly assess the potential spillover effects of spousal job loss on the mental health of both husbands and wives.

It is also important to bear in mind that the impact of job loss is likely to depend on family circumstances. Previous research, for example, indicates that unemployment affects family well-being by increasing financial stress (e.g., Atkinson et al. 1986; Broman et al. 1990), reducing economic security (e.g., Farber 1993; Jacobson et al. 1993; Stevens 1997), generating marital conflict (e.g., Conger and Elder 1994), and increasing the likelihood of divorce (e.g., Charles and Stephens 2004; Hansen 2005; Doiron and Mendolia 2012; Eliason 2012). Thus, we can expect that the mental health consequences of involuntary job loss will be shaped by the personal and financial situation that families find themselves in at the time the job loss occurs.

Unfortunately, most previous studies either provide only correlational evidence based on cross-sectional data or, if using longitudinal evidence, rely on very small samples (see Ström 2003). We are aware of only four studies that attempt to provide more causal estimates of the mental health consequences of spousal job loss by estimating panel data models using longitudinal data drawn from larger population-representative samples.

Clark (2003) used data from the first seven waves of the British Household Panel Survey (BHPS) and found that the mental health (measured using a dichotomous variable derived from the General Health Questionnaire (GHQ)) of women (but not men) was sensitive to changes in the employment status of their partners. This research, however, was distinct in that it did not identify the mechanism through which unemployment occurs.

Siegel et al. (2003), on the other hand, specifically analysed involuntary job loss. Using data from the first three waves of the US Health and Retirement Study (HRS), they found no evidence that husbands' involuntary job loss had a statistically significant effect on wives' mental health (as measured by the CES-Depression scale). The HRS sample, however, is restricted to households in which, at baseline, at least one household member was aged between 50 and 61. As job loss for many older workers may be a trigger for early retirement (Chan and Stevens 2004), these findings may simply indicate that job loss ending in retirement may have less severe mental health consequences since most evidence suggests that retirement improves mental health status (Eibich 2015).

More relevant is Marcus (2013) who used data (drawn from nine waves of the German Socio-Economic Panel) covering a much broader population-the German population aged between 18 and 62-to consider the effect of entry into 
unemployment as a result of plant closure. Using a combination of matching and difference-in-differences, he found that unemployment as a result of plant closure decreased the mental health (as measured by the mental component summary scale from the SF-12) of spouses almost by as much as it did their job-losing partner. Furthermore, the mental health consequences of job loss were more severe when it was the husband rather than the wife who lost their job. It is important to note, however, that his outcome of interest was not simply job loss but remaining in unemployment until at least the next survey wave confounding the mental health effects of the initial job loss with those resulting from the difficulty in regaining work. Plant closures are also typically known well in advance generating potential selectivity in the group of workers who remain in the plant long enough to be subject to its closure.

Finally, Mendolia (2014) analysed data on working-age couples from 14 waves of the BHPS. Utilising fixed effects estimation methods, she found that the mental health (as measured by the GHQ) of both partners declined following the husband being made redundant from his job. In contrast to the findings of Marcus (2013), the decline was still noticeably larger for husbands' own health.

It is also clear that parental unemployment can have adverse consequences for children. This is particularly true if the negative effects associated with income loss following unemployment outweigh the positive effect associated with an increase in the time parents have available to spend with their children or if there are negative consequences arising from a decline in parental well-being. Empirical research on the effects of parental unemployment on children, however, has tended to focus either on educational outcomes or on the physical health of children (see Ström 2003). Further, many of the studies often cited in support of the claim that parental unemployment adversely affects child well-being have focused not on parental unemployment but on some general measure of economic hardship or stressful event while growing up. There is, in fact, a surprisingly small body of evidence directly linking parental unemployment to indicators of the psychological well-being of children, with findings mostly suggesting relationships are either weak, often disappearing once other life events are controlled for or statistically insignificant (e.g., McMunn et al. 2001; Sund et al. 2003; Östberg et al. 2006; Piko and Fitzpatrick 2007; Fröjd et al. 2009). Also, with the notable exceptions of Johnson et al. (2012) and Schaller and Zerpa (2015), this evidence is based on crosssectional data and consequently tells us very little about causality.

Studies of children may also shed very little light on the consequences of parental job loss for older (i.e., adolescent and young-adult) children. Adolescents' growing independence and ability to think for themselves may make it difficult for parents to shield them from the effects of job loss. There is, for example, evidence that youths' perceptions of the family's financial situation are important in understanding the consequences of economic disadvantage for their schooling and mental health (Cobb-Clark and Ribar 2012).

There is also an important gender dimension to these relationships. In particular, psychologists have long been aware that the trajectories of depressive symptoms differ for adolescent boys and girls (Ge et al. 1994) and that in adolescence (as in early childhood), boys and girls respond differently to family economic problems (see Conger et al. 1993). Importantly, Ge et al. (1994) found that changes in uncontrollable events are associated with increases in depressive symptoms among adolescent girls 
but not among adolescent boys. More recent research has found a negative association between the father's, but not the mother's, unemployment and adolescents' self-reported health, suggesting that parental gender matters as well (Bacikova-Sleskova et al. 2015).

The two studies most closely related to ours exploited longitudinal population data to investigate the impact of parental job loss on children's overall subjective well-being rather than on mental health per se. Powdthavee and Vernoit (2013) found that parental job loss actually has a positive effect on the happiness of younger children (aged 11) in the UK, but either an insignificant or a strongly negative effect as children age. Kind and Haisken-DeNew (2012), on the other hand, found a significant decline in the life satisfaction of co-resident, young (ages 17 to 25) German males, but not females, following their fathers' job loss.

Our research makes an important contribution by providing high-quality longitudinal evidence that links job loss to changes in the mental health of other family members and accounts for potential endogeneity using a measure of involuntary job loss. Unlike most previous studies, we analyse the mental health consequences of partners' job loss for both husbands and wives and are unique in also examining how parental job loss affects the mental health of adolescent and young-adult children. We also carefully consider whether continued non-employment, financial stress, and relationship dissatisfaction compound the mental health impacts of job loss. Finally, our Australian evidence adds depth to the existing evidence which to date has drawn mainly on UK and German experiences. Australia is characterised by a regulated labour market with high minimum wages (Bray 2013), a strong public health system (Mossialos et al. 2016), and a welfare system with low, and essentially flat-rate, entitlement levels that provides universal cash benefits to those most in need (Whiteford 2010), making it a particularly interesting case for studying the effects of job loss on mental health.

\section{Estimation strategy}

We begin with a conceptual framework in which individuals' mental health is driven by their own characteristics (e.g., personality or gender), the life outcomes they experience (e.g., own employment outcomes), and the family circumstances (e.g., family job loss) in which they find themselves. With this framework in mind, our goal is to understand the pathways through which involuntary job loss affects the mental health of family members and in particular spouses and adolescent/young-adult children.

Our estimation strategy can be illustrated by referencing a two-way error component model that includes both individual and family heterogeneity. Specifically, we assume that mental health outcomes are given by

$$
y_{i j t}=\alpha+\beta \text { jobloss }_{j t-1}+x_{i j t} \pi+c_{j t} \gamma+w_{i j} \delta+z_{j} \theta+u_{i j t}
$$

where $y_{i j t}$ is the mental health of individual $i$ in family $j$ at time $t$, jobloss $_{j t-1}$ is an indicator for a family member's job loss sometime since the last interview, and $x_{i j t}$ and $c_{j t}$ denote vectors of time-varying individual and family characteristics, respectively, while $w_{i j}$ and $z_{j}$ are vectors of time-invariant individual and family characteristics.

The specification of the error term $\left(u_{i j t}\right)$ is fundamental to understanding the identification assumptions necessary to achieve causal identification of $\gamma$ (the coefficient of interest) and the other parameters in the model. Despite the rich set of individual- and family-level characteristics included in the estimation, there remains the possibility that 
unobserved factors correlated with both involuntary job loss and a family member's mental health may lead our estimates to be biased. We therefore allow for the following error structure:

$$
u_{i j t}=m_{i j}+f_{j}+\varepsilon_{i j t}
$$

where $m_{i j}$ denotes the time-invariant heterogeneity among individuals within families, $f_{j}$ captures the time-invariant heterogeneity among families, and $\varepsilon_{i j t}$ is the global error term.

We estimate two separate models. The first assesses the effect of one partner's involuntary job loss on his or her spouse's mental health, while the second captures the effect of parental job loss on adolescent children. Our spousal analysis takes couples as the family unit. The structure of our estimation sample (see below) implies that each individual is observed to be part of only one unique couple and, hence, individual $\left(m_{i j}\right)$ and family $\left(f_{j}\right)$ heterogeneity will be indistinguishable once we estimate the model separately by gender. Accounting for individual heterogeneity using a one-way error component model will therefore be robust to any time-invariant, individual-, or family-level heterogeneity that is correlated with spouses' mental health (Chatterji et al. 2014; Kim and Frees 2006).

Consequently, we analyse the effect of one partner's job loss on the other partner's mental health by estimating Eq. (3) using individual fixed effects:

$$
y_{i j t}=\alpha+\beta \text { jobloss }_{j t-1}+x_{i j t} \pi+c_{j t} \gamma+m_{i}+\varepsilon_{i j t}
$$

Our analysis of adolescents' mental health defines the family unit to be one parent (either the father or the mother) and all adolescent children in the household. The model is then estimated separately for mothers' and fathers' job loss. Each adolescent is, therefore, matched to a single family unit (i.e., parent), though in some cases, there may be multiple children observed in each family. The presence of siblings within a "family" permits the estimation of family fixed effects models, allowing us to test for family-specific, as well as individual-specific, heterogeneity using a standard Hausman test (see Kim and Frees 2006). We find evidence for both. Thus, as before, we estimate Eq. (3) accounting for individual-specific fixed effects in order to eliminate the bias associated with any time-invariant, individual-, or family-specific heterogeneity.

Our estimation strategy, therefore, relies on detailed controls and fixed effects regression to do much of the work in eliminating any threats to causality. We focus on the effects of pre-determined (lagged) job loss to avoid any reverse causality. Together, these imply that the main threat to causality is, as usual, the possibility that there are unobserved time-varying factors that simultaneously influence respondents' current mental health and their family members' previous job loss. Controlling for such selection events is widely accepted as being crucial in studies of the effects of job loss on own mental health (e.g., Eliason and Storrie 2009; Kuhn et al. 2009), but the need for this is far less obvious when studying the mental health of others. Nevertheless, our solution to this potential problem is to confine our attention to job loss events which are involuntary and therefore plausibly exogenous. Finally, we test the robustness of our findings by estimating (i) models which rely on an alternative measure of job loss that is both involuntary and unexpected and (ii) placebo regressions. 
The above estimation strategy allows us to generate (arguably) causal estimates of the effect of job loss overall on family members' mental health. At the same time, we are also interested in shedding light on the potential channels through which family job loss filters through the family. As noted earlier, previous research has suggested that unemployment affects family well-being by increasing financial stress and marital conflict. We thus create a series of indicators that allow us to estimate the disparity in mental health outcomes following job loss in families experiencing (i) continued nonemployment, (ii) financial stress, and (iii) relationship dissatisfaction. We also investigate whether or not sons and daughters are affected differently by the unemployment experienced by their fathers as opposed to their mothers. While gender is exogenous, unemployment length, financial stress, and relationship quality are not. We minimise the potential for endogeneity to confound our results by differentiating couples on the basis of pre-determined financial stress and relationship dissatisfaction experienced prior to job loss. This approach is not clearly possible in the case of ongoing unemployment. Consequently, we regard these as descriptive results which are useful in highlighting the potential pathways through which involuntary job loss affects family members' mental health.

\section{Data}

\subsection{Estimation sample}

The data used in this analysis come from release 12 of the Household, Income and Labour Dynamics in Australia (HILDA) Survey, a household panel survey that has been following members of a national probability sample of around 7700 Australian households annually since 2001 (see Watson and Wooden 2012). The response rate of inscope households was $66 \%$ in the initial wave, and re-interview rates in subsequent waves have consistently exceeded $87 \%$. We use data from waves 2 to 12 (i.e., 2002 to 2012) with the estimation sample restricted to waves 2 to 11 and wave 12 data used to construct a control for panel attrition. Wave 1 data are not used due to the lack of information regarding the reasons for job loss during the preceding year.

To identify the impact of job loss on different family members, two separate samples are generated: (i) persons living in couple relationships and (ii) adolescent-parent pairs. For the couple's sample, we select individuals with married or de facto partners of the opposite sex and impose an age restriction such that both partners are aged between 20 and 64 . We then select only the person-year observations relating to each individual's first partner, which results in omitting approximately $2.5 \%$ of the sample. While most HILDA Survey data are collected via personal interview, the measure of mental health comes from a separate self-completion questionnaire (SCQ), so we restrict the sample to persons who completed an SCQ, leading to the loss of 4165 (7.3\%) person-year observations. ${ }^{3}$ Finally, in order to minimise the potential for relationship breakdown following job loss to bias our results, we retain as many couples as possible in the sample for one survey wave following separation. ${ }^{4}$ The estimation sample comprises 4934 couples and 52,842 person-year observations.

We follow a similar procedure in constructing the sample of adolescent-parent pairs. We select all persons aged 15 to 20 years-for simplicity, referring to this group as "adolescents"-living with at least one parent, where "parent" means the parental figure 
of the household in which the adolescent (or young adult) resides, and may refer to a natural, adoptive, step, or foster parent or a parent's de facto partner. We then retain person-year observations relating only to the adolescent's first father and/or first mother identified in the data, which results in the omission of fewer than 50 personyear observations. We again restrict the sample to persons (i.e., "adolescents") who completed the SCQ, resulting in the exclusion of a further 1446 person-year observations (11.8\%). Finally, we retain as many parent-adolescent pairs as possible for one wave following an adolescent moving out of home. ${ }^{5}$ The initial adolescent-parent sample consists of 3553 adolescents and 10,792 person-year observations.

\subsection{Mental health}

Our outcome variable is the Mental Health Inventory (MHI-5), a sub-scale of the Short Form (SF-36) Health Survey (see Ware et al. 2000). It consists of five items (scored on a 6-point scale) that assess the frequency of anxiety and mood disturbance symptoms over the 4-week period preceding the interview. The five items are the following: (i) Have you been a nervous person; (ii) Have you felt so down in the dumps that nothing could you cheer up; (iii) Have you felt calm and peaceful; (iv) Have you felt down; and (v) Have you been a happy person. Like all SF-36 sub-scales, raw scores on each item are summed and then transformed so that the scale values range from 0 to 100 , with relatively low scores indicative of worse mental health.

The MHI- 5 has been shown to be an effective screening instrument in large populations for persons with mental health problems, in particular mood and anxiety disorders (e.g., Yamazaki et al. 2005; Cuijpers et al. 2009). The MHI-5 performs as well as, if not superior to, other self-assessed survey-based health scales, such as the General Health Questionnaire (McCabe et al. 1996; Hoeymans et al. 2004) and the Hopkins Symptom Checklist (Strand et al. 2003).

\subsection{Involuntary job loss}

Our measure of involuntary job loss is based on responses to questions asking respondents who changed employers or ceased working since the last interview about the main reason they left their previous job. Using this data, we create an indicator which takes the value 1 if an employment termination has occurred since the previous interview due to lay-off, retrenchment, redundancy, dismissal, or an employer going out of business. Additionally, any self-employed persons who reported that their business closed down for economic reasons are classified as experiencing involuntary job loss.

We observe a total of 1262 involuntary job loss events in the couple sample (807 males and 455 females) and 466 events in the adolescent sample. The size of the "treatment group" is thus larger than available in earlier studies, increasing estimation precision.

Our measure of involuntary job loss compares favourably to others used in the literature. In particular, Siegel et al. (2003) and Mendolia (2014) both adopted a narrower definition of job loss by restricting their analyses to only those made redundant, arguing that redundancies are not the consequences of worker behaviour. In contrast, Marcus (2013) restricted his analysis even further to consider only job losses resulting from plant closures, ruling out partial closures and downsizing on the grounds that 
both will lead to selective retrenchments with less productive workers laid off first. Plant closures are rarely exogenous shocks; however, they are usually planned and announced well in advance, also generating selective retrenchment by allowing those with better options to quit-and hence avoid retrenchment-prior to the closure date. In contrast, our approach is to aggregate across multiple forms of involuntary job loss in order to generate a measure that is less sensitive to specific selection effects. We then gauge the potential for selection effects overall to affect our analysis by considering the robustness of our results to an alternative measure of involuntary job loss which is also unexpected and by conducting placebo tests.

Like previous studies, one potential weakness of the job loss measure is that the precise date of job loss is not observed. We know only that the job loss event occurred between two interview dates. Given interview dates occur roughly 1 year apart (though there is variation around this), we therefore obtain estimates of the impact of job loss events that, on average, occurred about 6 months prior to interview. ${ }^{6}$

\subsection{Covariates}

The selection of time-varying covariates is based on previous longitudinal research analysing the determinants of mental health (e.g., Clark 2003; Mendolia 2014; Wooden and Li 2014). Specifically, our estimation models control for age (specified as a cubic when analysing spouses and as age fixed effects when analysing adolescents); household composition (numbers of children and adults); the presence of a long-term health condition and disability, other than mental illness (and differentiated by the extent to which the condition limits work); physical health; labour force status; preferred working hours (if employed); home ownership and real home equity; regional unemployment rates; location (a set of dummies identifying how distant the household is from a major Australian city); a measure of the socio-economic status advantage or disadvantage of the region (see ABS 2001); the presence of another adult during the survey interview; and an indicator for whether the sample member is a non-respondent at the next survey wave. Verbeek and Nijman (1992) propose the latter as a simple means of both testing, and controlling, for the selectivity bias that might arise from the sample attrition that occurs during the course of a panel. Finally, in the analyses of adolescent mental health, we include indicator variables to differentiate adolescents living in single-parent households and to identify full-time students.

We also wish to allow for heterogeneity in the effect of job loss associated with ongoing non-employment, financial stress, and relationship quality. We thus construct an indicator for being not employed at the interview following the job loss, which is hence measured contemporaneously with partners' mental health. We capture financial stress by using data collected in the SCQ about the occurrence of seven types of stressful financial events during the past year to generate two summary measures of financial stress. The first refers to cash flow problems stemming from at least one of the following occurring during the past year because of a shortage of money: inability to pay the rent or the mortgage, inability to pay utilities bills, and having to ask for financial help from friends or family. The second refers to financial hardship and involves experiencing at least one of the following because of a shortage of money: pawning or selling something, missing meals, inability to heat the home, and seeking help from welfare or community 
organisations. ${ }^{7}$ Our measures of financial stress are lagged one period and so capture financial stress at the interview prior to any job loss.

Respondents are also asked, within the SCQ, how satisfied they are with their relationship with their partner. We have reversed the response scale so that 0 indicates "completely satisfied" and 10 "completely dissatisfied." Like our financial stress measure, we also lag relationship satisfaction one period in order to capture relationship satisfaction at the interview prior to job loss.

The full list of covariates, together with definitions and summary statistics, is provided in Table 6 in Appendix.

\subsection{Descriptive statistics}

A comparison of mean unweighted MHI- 5 scores is presented in Table 1 and reveals that among men with wives that were employed at the time of the previous interview, mental health is lower if their wife had involuntarily lost her job since the previous interview (mean $=75.3$ ) than if their wife had not changed jobs (mean $=77.4)$, a difference that is statistically significant $(p=.003)$. A similar pattern is observed for wives' mental health, conditional on their husbands' employment status. The mean MHI-5 of wives of husbands who lost their jobs involuntarily is 71.5 , which compares with a mean score of 75.2 for wives of employed husbands who did not change employers. This difference is also statistically significant $(p<.001)$ but much larger than the comparable disparity in the MHI-5 scores of husbands.

Table 1 Mean MHI-5 scores (and standard deviations) by partner's employment status

\begin{tabular}{|c|c|c|c|c|c|c|}
\hline \multirow[t]{2}{*}{ A. Partner's employment status } & \multicolumn{3}{|c|}{ Husbands } & \multicolumn{3}{|l|}{ Wives } \\
\hline & Mean & SD & $N$ (persons) & Mean & SD & $N$ (persons) \\
\hline \multicolumn{7}{|l|}{ Employed at $t-1$} \\
\hline Lost job involuntarily & 75.3 & 16.1 & 395 & 71.5 & 17.8 & 663 \\
\hline Ceased a job for other reason & 76.6 & 15.2 & 1943 & 73.2 & 16.7 & 1796 \\
\hline Did not change jobs & 77.4 & 14.7 & 3364 & 75.2 & 15.7 & 3941 \\
\hline Not employed at $t-1$ & 74.1 & 17.7 & 2139 & 69.4 & 19.7 & 1126 \\
\hline \multirow[t]{2}{*}{ B. Parent's employment status } & \multicolumn{3}{|c|}{ Male children } & \multicolumn{3}{|c|}{ Female children } \\
\hline & Mean & SD & $N$ (persons) & Mean & SD & $N$ (persons) \\
\hline \multicolumn{7}{|l|}{ Father } \\
\hline \multicolumn{7}{|l|}{ Employed at $t-1$} \\
\hline Lost job involuntarily & 76.5 & 15.9 & 119 & 70.8 & 16.5 & 106 \\
\hline Ceased a job for other reason & 74.7 & 17.6 & 257 & 70.3 & 18.0 & 226 \\
\hline Did not change jobs & 76.5 & 15.3 & 1170 & 72.9 & 16.7 & 1133 \\
\hline Not employed at $t-1$ & 72.9 & 16.5 & 229 & 70.0 & 18.1 & 169 \\
\hline \multicolumn{7}{|l|}{ Mother } \\
\hline \multicolumn{7}{|l|}{ Employed at $t-1$} \\
\hline Lost job involuntarily & 77.6 & 15.1 & 98 & 67.3 & 19.6 & 100 \\
\hline Ceased a job for other reason & 75.0 & 16.3 & 348 & 71.2 & 17.7 & 343 \\
\hline Did not change jobs & 77.1 & 15.1 & 1177 & 72.7 & 16.5 & 1170 \\
\hline Not employed at $t-1$ & 75.0 & 16.4 & 558 & 71.0 & 17.9 & 537 \\
\hline
\end{tabular}


Turning to adolescents, MHI-5 scores of females are lower following parental job loss relative to the more usual case in which parents remain employed. In the case of maternal job loss, the difference is both large -5.5 points-and statistically significant $(p<.001)$. In contrast, male adolescents, on average, report no significant difference in MHI-5 scores following a father or mother involuntarily losing their job compared to their peers whose parents remain employed.

\section{Regression results}

\subsection{Couples}

Summary results from linear regression estimates of the effect of husbands' and wives' involuntary job loss on their partners' MHI-5 score are presented, for each of three specifications, in Table 2. The unconditional effect of job loss on partners' MHI-5 score is presented in column (1). In column (2), we control for all observed individual and family characteristics. Finally, column (3) is our preferred specification, which controls for observable individual and family characteristics as well as individual fixed effects.

The results indicate there is no discernible decline in husbands' mental health following their wives' involuntary job loss. The estimated mental health impact of wives' job loss is small in magnitude and statistically insignificant. This result is striking in its consistency across all specifications. In contrast, the mental health of wives whose husbands lose their jobs is, in the absence of individual fixed effects, 2.0 (or 0.12 of a standard deviation (SD)) to 2.7 (0.17 SD) points lower on the MHI-5 scale than for wives with continuously employed partners (see columns

Table 2 Effect of partner's job loss on mental health: selected OLS and fixed effects estimates

\begin{tabular}{llll}
\hline A. Husband's mental health & $(1)$ & $(2)$ & $(3)$ \\
Wife's job loss & -1.024 & -0.569 & -0.413 \\
& $(0.748)$ & $(0.694)$ & $(0.527)$ \\
Controls & No & Yes & Yes \\
Fixed effects & No & No & Yes \\
$R$-squared & 0.000 & 0.165 & 0.032 \\
Rho & & & 0.661 \\
Person-year observations & 26,065 & 24,849 & 24,849 \\
Job loss cases & 455 & 447 & 447 \\
B. Wife's mental health & $(1)$ & $(2)$ & $(3)$ \\
Husband's job loss & $-2.749^{* *}$ & $-2.039^{* *}$ & -0.706 \\
& $(0.590)$ & $(0.553)$ & $(0.441)$ \\
Controls & No & Yes & Yes \\
Fixed effects & No & No & Yes \\
$R$-squared & 0.001 & 0.150 & 0.023 \\
Rho & & & 0.638 \\
Person-year observations & 26,541 & 25,292 & 25,292 \\
Job loss cases & 807 & 798 & 798 \\
\hline
\end{tabular}

Notes: Standard errors reported in parentheses. The only coefficient estimates reported here are those for the main variable of interest-partner's job loss. A full set of coefficient estimates are available in Additional file 1 ${ }^{*} p<.05 ;{ }^{* *} p<.01$ 
1 and 2). Further, this difference is statistically significant at the $1 \%$ level. However, once we account for time-invariant individual-specific heterogeneity through the inclusion of individual fixed effects, the estimated impact of husbands' job loss on wives' mental health is substantially reduced and becomes statistically insignificant (column 3). The large magnitude of the rho parameter, which measures the fraction of the unexplained variance that is due to the fixed effects, indicates that controlling for individual fixed effects is important. Thus, in models that account for both observed and unobserved heterogeneity, we find no significant effect of men's or women's involuntary job loss on their partners' mental health. This is particularly striking given we would expect any endogeneity bias to lead us to overstate our results. While not reported, we also note that the control for panel attrition, which as expected is negatively signed, becomes insignificant once fixed effects are accounted for.

At first glance, these results appear inconsistent with other results that use panel data techniques to account for unobserved heterogeneity in mental health. Specifically, Marcus (2013) found that German plant closures were linked to a decline in the mental health of partners, with the estimated coefficients he obtained lying outside the confidence intervals obtained in our results. However, the estimated effects were modest-between 0.15 (men) and 0.20 (women) standard deviations in his main specification-and only weakly significant for men. The mental health effects of other types of dismissals were even smaller. Similarly, Mendolia (2014) concluded that, in the UK, women's mental health declined slightly $(0.12 \mathrm{SD})$ as a result of their husbands being made redundant, though not as a result of being dismissed or being in a temporary job that ends. Indeed, Mendolia's estimate is contained within the 95\% confidence interval around our pooled point estimate in Table 2 but lies just outside our confidence interval for our fixed effects estimate (column 3).

Although workers' involuntary job loss appears to have few effects on their partners' mental health overall, there are likely to be groups for whom a partner's job loss is particularly stressful. As noted earlier, previous researchers have suggested that job loss affects the mental health of family members through a variety of channels including financial stress and marital tension. We investigate this issue by examining whether or not the mental health effect of involuntary job loss varies across families experiencing (i) continued non-employment, (ii) financial stress, and (iii) relationship dissatisfaction. We again find no significant effects of wives' job loss on husbands' mental health. In contrast, significant effects of husbands' job loss on the mental health of wives are now found. We thus only report the results for wives' mental health (see Table 3), though do briefly discuss gender differences in responses.

We begin by interacting workers' involuntary job loss between $t-1$ and $t$ with an indicator for continued non-employment at time $t$ to assess whether job loss that results in a longer period of non-employment has a greater impact on partners' mental health. Key estimates are presented in panel A of Table 3. Women experience a larger, and statistically significant, decline in mental health (approximately 0.15 of a SD) if, by the next survey interview, their partners have still failed to secure alternative employment following involuntary job loss. Thus, the extent to which involuntary job loss, at least among husbands, diminishes their partners' mental health rests on how quickly those husbands secure alternative employment. 
Table 3 Heterogeneity in the effect of husbands' job loss on wives' mental health: selected OLS and fixed effects estimates

\begin{tabular}{|c|c|c|c|}
\hline A. Re-employment of husband & $(1)$ & (2) & (3) \\
\hline \multirow[t]{2}{*}{ Husband's job loss } & $-2.083^{* *}$ & $-1.501^{*}$ & -0.119 \\
\hline & $(0.672)$ & $(0.629)$ & $(0.499)$ \\
\hline \multirow[t]{2}{*}{ Husband's job loss $\times$ husband not employed } & $-3.117^{*}$ & -2.271 & $-2.492^{*}$ \\
\hline & $(1.372)$ & $(1.271)$ & $(0.993)$ \\
\hline Controls & No & Yes & Yes \\
\hline Fixed effects & No & No & Yes \\
\hline$R$-squared & 0.001 & 0.150 & 0.023 \\
\hline Rho & & & 0.638 \\
\hline Person-year observations & 25,614 & 25,292 & 25,292 \\
\hline Job loss cases (without re-employment/total) & 189/807 & 189/798 & $189 / 798$ \\
\hline B. Cash flow stress & $(1)$ & (2) & (3) \\
\hline \multirow[t]{2}{*}{ Husband's job loss } & $-1.806^{*}$ & -1.179 & 0.111 \\
\hline & $(0.764)$ & $(0.719)$ & $(0.568)$ \\
\hline \multirow[t]{2}{*}{ Husband's job loss $\times$ cash flow stress $(t-1)$} & -0.939 & -1.923 & $-2.866^{* *}$ \\
\hline & $(1.388)$ & $(1.306)$ & $(1.041)$ \\
\hline \multirow[t]{2}{*}{ Cash flow stress $(t-1)$} & $-7.141^{* *}$ & $-4.032^{* *}$ & -0.545 \\
\hline & $(0.276)$ & $(0.286)$ & $(0.284)$ \\
\hline Controls & No & Yes & Yes \\
\hline Fixed effects & No & No & Yes \\
\hline$R$-squared & 0.032 & 0.159 & 0.022 \\
\hline Rho & & & 0.639 \\
\hline Person-year observations & 22,124 & 21,262 & 21,262 \\
\hline Job loss cases (with cash flow stress $(t-1) /$ total) & 203/661 & $200 / 654$ & $200 / 654$ \\
\hline C. Financial hardship & $(1)$ & (2) & (3) \\
\hline \multirow[t]{2}{*}{ Husband's job loss } & $-2.343^{* *}$ & $-1.629^{*}$ & -0.391 \\
\hline & $(0.671)$ & $(0.634)$ & $(0.503)$ \\
\hline \multirow[t]{2}{*}{ Husband's job loss $\times$ financial hardship $(t-1)$} & -1.543 & -3.115 & $-4.745^{*}$ \\
\hline & $(2.136)$ & $(2.005)$ & $(1.704)$ \\
\hline \multirow[t]{2}{*}{ Financial hardship $(t-1)$} & $-11.937^{* *}$ & $-6.470^{* *}$ & -0.642 \\
\hline & $(0.442)$ & $(0.452)$ & $(0.429)$ \\
\hline Controls & No & Yes & Yes \\
\hline Fixed effects & No & No & Yes \\
\hline$R$-squared & 0.035 & 0.160 & 0.022 \\
\hline Rho & & & 0.639 \\
\hline Person-year observations & 22058 & 21196 & 21196 \\
\hline Job loss cases (with financial hardship $(t-1) /$ total) & $66 / 660$ & $66 / 653$ & $66 / 653$ \\
\hline D. Dissatisfaction with partner & $(1)$ & (2) & (3) \\
\hline \multirow[t]{2}{*}{ Husband's job loss } & -0.966 & -0.290 & 0.126 \\
\hline & $(0.828)$ & $(0.775)$ & $(0.633)$ \\
\hline \multirow[t]{2}{*}{ Husband's job loss $\times$ dissatisfied with partner $(t-1)$} & $-0.733^{*}$ & $-0.686^{*}$ & -0.408 \\
\hline & $(0.289)$ & $(0.269)$ & $(0.221)$ \\
\hline \multirow[t]{2}{*}{ Dissatisfied with partner $(t-1)$} & $-2.035^{* *}$ & $-1.832^{* *}$ & $-0.279^{* *}$ \\
\hline & $(0.054)$ & $(0.053)$ & $(0.061)$ \\
\hline
\end{tabular}


Table 3 Heterogeneity in the effect of husbands' job loss on wives' mental health: selected OLS and fixed effects estimates (Continued)

\begin{tabular}{llll}
\hline Controls & No & Yes & Yes \\
Fixed effects & No & No & Yes \\
R-squared & 0.060 & 0.194 & 0.025 \\
Rho & & & 0.632 \\
Person-year observations & 24,357 & 23,572 & 23,572 \\
Job loss cases & 726 & 719 & 719 \\
\hline
\end{tabular}

Notes: Standard errors reported in parentheses ${ }^{*} p<.05 ;{ }^{* *} p<.01$

We next consider whether or not the impact of job loss on mental health varies with a household's financial situation, as reflected in our two indicators of financial stress (panels B and C). Surprisingly, while financial stress that results in either cash flow problems or financial hardship is related to poorer mental health, once we account for individual-specific fixed effects, the associations become statistically insignificant. More importantly though, there is strong evidence that women in financially stressed households experience a large deterioration in mental health if their partners lose their jobs involuntarily. This effect is particularly large if the family was experiencing financial hardship (0.29 SD) but is also evident if the family experienced cash flow problems (0.17 SD).

Finally, we consider whether or not the relationship between respondents' mental health and their partners' job loss depends on the level of their relationship dissatisfaction prior to the job loss (see panel D). Both men and women report poorer current mental health the more dissatisfied they were with their partners at the previous interview. Men's mental health response to their partners' involuntary job loss (not reported), however, does not depend on their satisfaction with their partners. In contrast, there is some evidence that women who were highly dissatisfied with their partners experience a larger drop in mental health as a result of their partners' job loss than do women who were completely satisfied with their partners. However, this effect, while relatively large (bearing in mind that marital dissatisfaction is measured on an 11-point scale), is only weakly significant (i.e., at the $10 \%$ level) in our preferred specification.

\subsection{Adolescents}

Key results from the separate estimations of the effect of father's and mother's involuntary job loss on adolescent mental health are presented in Table 4. As before, we present results from three different specifications. Results for paternal job loss are presented in panel A, while results for maternal job loss are reported in panel B.

We find no support for the hypothesis that a father's job loss affects their adolescent children's mental health. Similarly, the effect of maternal job loss (see panel B) while negative is statistically insignificant once individual fixed effects are taken into account. There is no evidence that parental job loss affects the mental health of adolescents overall.

We next assess whether there is heterogeneity in the effects of parental job loss. Specifically, we consider whether the effect of parental job loss on adolescents' 
Table 4 Effect of parental job loss on adolescent mental health: selected OLS and fixed effects estimates

\begin{tabular}{llll}
\hline A. Effect of father's job loss & $(1)$ & $(2)$ & $(3)$ \\
Father's job loss & -0.422 & -0.777 & -0.116 \\
& $(1.064)$ & $(1.041)$ & $(0.968)$ \\
Controls & No & Yes & Yes \\
Fixed effects & No & No & Yes \\
R-squared & 0.000 & 0.063 & 0.020 \\
Rho & & & 0.594 \\
Person-year observations & 8098 & 7805 & 7805 \\
Job loss cases & 245 & 242 & 242 \\
B. Effect of mother's job loss & $(1)$ & $(2)$ & $(3)$ \\
Mother's job loss & -1.927 & $-2.324^{*}$ & -0.534 \\
& $(1.120)$ & $(1.101)$ & $(1.033)$ \\
Controls & No & Yes & Yes \\
Fixed effects & No & No & Yes \\
R-squared & 0.000 & 0.060 & 0.017 \\
Rho & & & 0.589 \\
Person-year observations & 10,056 & 9722 & 9722 \\
Job loss cases & 221 & 220 & 220 \\
\hline
\end{tabular}

Notes: Standard errors reported in parentheses. Full coefficient estimates are available in Additional file 1 ${ }^{*} p<.05 ;{ }^{* *} p<.01$

psychological well-being depends on whether the parent is able to find alternative employment before the next survey interview or on the adolescent's gender. Summary results are reported in Table 5.

Adolescents whose fathers experience job loss have slightly worse mental health if their fathers are not employed at the next interview than if they have returned to work, though this disparity is not statistically significant (see panel A, Table 5). Both groups of adolescents report mental health scores that are statistically equivalent to their peers whose fathers did not lose their jobs. In contrast, adolescents report much worse mental health if their mothers fail to return to work following job loss (panel B, Table 5). In particular, the MHI- 5 scores of adolescents are 6.6 points lower if their mothers remain out of work than if they have returned to work by the next interview. This effect is larger than the estimated impact of all other control variables and is equivalent to around .40 of one SD in the MHI- 5 score.

We also examine the possibility that the effects of parental job loss may differ depending on the adolescent's gender. Adolescent girls have MHI-5 scores following their fathers' job loss which are substantially lower (approximately 2.3 points or $0.14 \mathrm{SD}$ ) than adolescent boys whose fathers also lost their jobs (panel C, Table 5). The magnitude of this effect, however, is much smaller once individual-specific fixed effects are controlled for, implying that we cannot reject the hypothesis that this difference is zero. In the case of maternal job loss, however, the gender gap in adolescents' mental health is both larger ( 5 points or $0.31 \mathrm{SD}$ ) and statistically significant, even after we control for unobserved, time-invariant heterogeneity (panel D, Table 5). Thus, we find that the 
Table 5 The effect of parental job loss on adolescents' mental health by parental re-employment and adolescent gender: selected OLS and fixed effects estimates

\begin{tabular}{|c|c|c|c|}
\hline A. Re-employment of father & (1) & (2) & (3) \\
\hline \multirow[t]{2}{*}{ Father's job loss } & -0.297 & -0.654 & 0.024 \\
\hline & $(1.213)$ & $(1.188)$ & $(1.089)$ \\
\hline \multirow[t]{2}{*}{ Father's job loss $\times$ father not employed } & -0.543 & -0.514 & -0.613 \\
\hline & $(2.463)$ & $(2.388)$ & $(2.186)$ \\
\hline Controls & No & Yes & Yes \\
\hline Fixed effects & No & No & Yes \\
\hline$R$-squared & 0.000 & 0.063 & 0.020 \\
\hline Rho & & & 0.594 \\
\hline Person-year observations & 7954 & 7805 & 7805 \\
\hline Job loss cases (without re-employment/total) & $58 / 245$ & $58 / 242$ & $58 / 242$ \\
\hline B. Re-employment of mother & (1) & (2) & (3) \\
\hline \multirow[t]{2}{*}{ Mother's job loss } & -0.263 & -0.661 & 1.963 \\
\hline & $(1.406)$ & $(1.380)$ & $(1.293)$ \\
\hline \multirow[t]{2}{*}{ Mother's job loss $\times$ mother not employed } & $-4.527^{*}$ & $-4.459^{*}$ & $-6.559^{* *}$ \\
\hline & $(2.292)$ & $(2.230)$ & $(2.046)$ \\
\hline Controls & No & Yes & Yes \\
\hline Fixed effects & No & No & Yes \\
\hline$R$-squared & 0.001 & 0.060 & 0.019 \\
\hline Rho & & & 0.590 \\
\hline Person-year observations & 9912 & 9722 & 9722 \\
\hline Job loss cases (without re-employment/total) & $82 / 221$ & $82 / 220$ & $82 / 220$ \\
\hline C. Father's job loss interacted with gender of child & (1) & (2) & (3) \\
\hline \multirow[t]{2}{*}{ Father's job loss } & 2.296 & 1.678 & 0.969 \\
\hline & $(1.460)$ & $(1.428)$ & $(1.296)$ \\
\hline \multirow[t]{2}{*}{ Father's job loss $\times$ female } & $-5.691^{* *}$ & $-5.121^{*}$ & -2.404 \\
\hline & $(2.096)$ & $(2.040)$ & $(1.911)$ \\
\hline Controls & No & Yes & Yes \\
\hline Fixed effects & No & No & Yes \\
\hline$R$-squared & 0.001 & 0.063 & 0.020 \\
\hline Rho & & & 0.594 \\
\hline Person-year observations & 8098 & 7805 & 7805 \\
\hline Job loss cases (for female adolescent/total) & $117 / 245$ & $116 / 242$ & $116 / 242$ \\
\hline D. Mother's job loss interacted with gender of child & (1) & (2) & (3) \\
\hline \multirow[t]{2}{*}{ Mother's job loss } & $3.298^{*}$ & 2.649 & 1.985 \\
\hline & $(1.584)$ & $(1.552)$ & $(1.440)$ \\
\hline \multirow[t]{2}{*}{ Mother's job loss $\times$ female } & $-10.310^{* *}$ & $-9.775^{* *}$ & $-5.064^{*}$ \\
\hline & $(2.213)$ & $(2.152)$ & $(2.018)$ \\
\hline Controls & No & Yes & Yes \\
\hline Fixed effects & No & No & Yes \\
\hline$R$-squared & 0.002 & 0.062 & 0.018 \\
\hline
\end{tabular}


Table 5 The effect of parental job loss on adolescents' mental health by parental re-employment and adolescent gender: selected OLS and fixed effects estimates (Continued)

\begin{tabular}{llll}
\hline Rho & & 0.589 \\
Person-year observations & 10056 & 9722 & 9722 \\
Job loss cases (for female adolescent/total) & $112 / 221$ & $112 / 220$ & $112 / 220$ \\
\hline
\end{tabular}

Notes: Standard errors reported in parentheses

${ }^{*} p<.05 ;{ }^{* *} p<.01$

mental health of daughters is much more affected by parental job loss than is that of sons, and this is especially so in the case of maternal job loss. These findings are inconsistent with Kind and Haisken-DeNew (2012), who found that the life satisfaction of young German men suffers more as a result of their parents' job loss than does that of their female peers. They are, however, consistent with a very different line of research that has found that young females are more responsive than young males to stressful life events (e.g., Ge et al. 1994; Bouma et al. 2008).

\subsection{Robustness}

We also conducted a number of additional estimations involving different specifications and samples in order to establish the robustness of our key findings. The results of these additional estimations are described briefly here, but without any reporting of coefficient estimates. These, however, can be found in Additional file 1.

First, and perhaps most critically, we have assumed that our measure of involuntary job loss is exogenous. That is, our maintained assumption is that our control variables effectively capture all of the time-varying factors simultaneously affecting individuals' prior job loss and their family members' current mental health. Others (notably Marcus 2013) argue that this assumption is more plausible if job loss is the result of a business closure. The HILDA Survey data, however, do not enable job loss due to business closures to be separately identified. Fortunately, employees are asked about the expected probability of losing their job through being retrenched, being fired, or not having their contract renewed during the year ahead. This allows us to identify workers for whom job loss was largely unanticipated, increasing the chances that the job loss workers experience is exogenous. We thus replicated our analysis using an alternative job loss indicator which equals one only for individuals who reported involuntarily losing their job since the previous survey and who also reported, at the previous interview, that there was a $0 \%$ chance of job loss in the year ahead.

We find that the effects of unexpected involuntary job loss largely mirror those of involuntary job loss overall. Specifically, we find no evidence that a husband's mental health is adversely affected by his wife's unexpected job loss. This is true irrespective of whether or not the wife remains not employed or the couples' degree of relationship dissatisfaction. ${ }^{8}$ Similarly, husbands' unexpected involuntary job loss has no significant effect on their wives' reported mental health overall. As before, wives do have significantly poorer mental health if their husbands lose their jobs and remain out of work rather than finding new employment. Importantly, this differential is substantially 
larger when the job loss was unexpected. The disparity in wives' mental health outcomes associated with experiencing financial stress and relationship dissatisfaction in combination with their husbands' unexpected involuntary job loss is similar in magnitude to that associated with involuntary job loss overall but becomes statistically insignificant. Finally, and consistent with our previous results, we find little evidence that adolescents' mental health is negatively affected by their parents' involuntary job loss even when it is unexpected.

To further test our identification assumption, we follow Marcus (2013) in repeating our analysis using placebo regressions in which we pretend that any observed involuntary job loss takes place either (i) 1 year or (ii) 2 years earlier than it in fact did. This effectively involves replacing the measure of recent job loss with a measure of job loss in the year ahead (and separately, 2 years ahead) allowing us to investigate any trends in mental health before job loss occurs. As expected, we find that the significant mental health penalties associated with job loss discussed above disappear when we use the placebo job loss measure. Thus, our results are driven by the actual timing of job loss rather than any prior downward trajectory in the mental health of family members.

We also checked the robustness of our results against alternative sampling restrictions and model specifications. These tests involved sequentially re-defining the partner age group to 20 to 55 years, omitting all cases where the partner was self-employed at $t-1$, controlling for a measure of household disposable income, restricting the number of covariates to a more parsimonious (and arguably more exogenous) set, and removing all time-varying covariates (and hence only controlling for individual fixed effects). Results in all cases are qualitatively unchanged, suggesting the lead-up to retirement does not influence our results, the impact of job loss operates through channels other than income, and our results are not unduly biased by the inclusion of covariates that might be endogenous. Further, we find insignificant differences in the effect of parental job loss in (i) single-person versus couple households and (ii) families in which adolescents do and do not report financial stress.

In addition, to get a sense of how job loss affects the incidence of severe depressive symptoms, we re-estimated our models with a binary indicator of severe depressive symptoms. The indicator is based on previous research which suggests that a MHI-5 score equal to or below 52 indicates severe depressive symptoms (e.g., Yamazaki et al. 2005). Findings suggest that a partner's job loss increases the probability of experiencing severe depressive symptoms by 1 percentage point (or 8 to 13\%), though as before effects are statistically insignificant. For wives, the chance of experiencing depressive symptoms after their husbands' job loss is approximately $64 \%$ greater if the family is already experiencing cash flow problems than if it is not, while for adolescents, the incidence of depressive symptoms is $82 \%$ higher for girls relative to boys when a mother loses their job and $73 \%$ higher overall when mothers are not reemployed quickly.

Finally, we also investigated the longer run implications of job loss for mental health by re-estimating our main specifications including a measure of job loss lagged one period. ${ }^{9}$ In almost all cases, the substantive effect of recent job loss remains virtually unchanged and there is no evidence of long-term mental health effects of spousal and parental job loss. The exception is that the negative impact of husbands' recent job loss 
with women's mental health is statistically significant and somewhat larger in absolute magnitude, while lagged job loss is also associated with a significant reduction in women's mental health.

\section{Discussion and conclusions}

Mental illness is a pressing labour market issue. Much of the economic and social cost of mental illness stems from reduced economic participation and diminished productivity. Moreover, mental illness may have indirect effects on family members, communities, and society more generally, which will magnify the mental health costs associated with poor labour market outcomes.

Our paper makes an important contribution in quantifying these effects by analysing the impact of involuntary job loss on the mental health of family members. We find no evidence that husbands' mental health is affected by their wives' job loss. Wives' mental health deteriorates, however, following their husbands' job loss, but the magnitude of this decline is only statistically significant if their husbands experience a sustained period of non-employment or if the couple experienced financial hardship or relationship strain prior to the husband losing his job. We also find that co-resident adolescent children's mental health is unaffected by their fathers' job loss. Adolescents' mental health declines, however, after their mothers' job loss, but only if they experience a period of sustained non-employment. Finally, it is adolescent girls rather than boys who are sensitive to their mothers' job loss.

We can only speculate about the explanation for men and women's differential responses to their partners' involuntary job loss. Becker's (1981) marriage model, for example, postulates that men have a comparative advantage in market production, while women's comparative advantage lies in home production. The gendered nature of individuals' comparative advantage results in specialisation within families, with women focused largely on home production and men focused largely on market work. Given this, couples may find it easier to maintain total household surplus if the wife, rather than the husband, loses her job, because she can exploit her comparative advantage and dramatically increase home production in the form of child care, domestic chores, and the like. Time-use studies, for example, suggest that wives' unemployment is associated with an increase in hours spent in housework that is double the increase for unemployed husbands (Gough and Killewald 2011). In addition, household surplus may decline more when husbands lose their jobs because men are less able to compensate for the loss of their market income by increasing home production. These tendencies will be further reinforced by gender differences in labour market outcomes, in particular earnings (Blau et al. 2014) and traditional gender identity norms (Fortin 2005; Bertrand et al. 2015).

There are also more behavioural explanations for gendered mental health responses to family members' job losses. There is evidence, for example, that women experience negative emotions more intensely (Fujita et al. 1991; Brody 1993), have greater empathic concern for others (Kessler and McLeod 1984), and are more likely to take on the burdens of other family members than are men (Kessler et al. 1985; Rohrbaugh et al. 2002). Consequently, women are more likely to be sensitive 
to the distress of men than men are to the distress of women (Belle 1987; Cross and Madson 1997). In particular, Howe et al. (2004) study job loss within couples and conclude that "when a man loses a job the associated stresses of unemployment and financial strain are taken on as common burdens by both members of the couple, whereas when a woman loses a job she may be more likely to face those burdens alone" (p. 648).

It is also important to consider why the mental well-being of adolescent children is responsive to their mothers' job loss but not to that of their fathers. Indeed, it could be argued that this result is counter-intuitive given that, in the large majority of couple households, men continue to be the primary breadwinner (Drago et al. 2005). Since we do not control for income in our preferred specification, any drop in income associated with job loss is captured in the estimated effect of job loss itself. Thus, it appears that parental job loss affects adolescents' mental health through channels other than income levels. Interestingly, Kalil and Ziol-Guest (2005) reach a similar conclusion when assessing the impact of (single) mothers' unemployment on adolescents' non-cognitive skills and educational attainment.

One potential explanation lies in the different influence mothers and fathers have over the adolescent's consumption. There is substantial evidence, especially not only from developing countries (World Bank 2012) but also from developed nations (e.g., Lundberg et al. 1997), that household members do not always pool their incomes perfectly and that children do better when mothers control a relatively large fraction of family resources. The loss of job by the mother results in a loss of her labour income and potentially a loss of bargaining power over how remaining household resources are consumed. Consequently, the adolescent's consumption may fall. Lower consumption together with the realisation that their family is experiencing economic hardship may then contribute to a decline in the adolescent's psychological well-being. On the other hand, when fathers lose their job, mothers may be more inclined to shield adolescents by maintaining their consumption levels and finding savings elsewhere.

Alternatively, the explanation may lie in inter-family relationships more generally. Adolescents spend more time with their mothers than their fathers, and any time spent with their father usually involves more leisure activities than care-giving roles (Collins and Russell 1991). Perhaps as a result, mothers and adolescents, particularly mothers and daughters, are more frequently engaged in conflict within the household (Paikoff and Brooks-Gunn 1990; Allison 2000). More generally, Steinberg and Silk (2002, p. 117), drawing on evidence provided by, among others, Montemayor et al. (1993), Larson and Richards (1994), and Laursen (1995), conclude that "adolescents' relationships with their mothers are more intense than those with fathers; this intensity includes not only greater closeness but also more charged and more frequent conflict." Given this, it is perhaps not surprising that mothers' job loss is experienced most deeply by their adolescent daughters.

Whatever the source of these differential effects, our analysis leads us to two important conclusions. First, generating sensible estimates of the indirect effects of job loss on family members' mental health requires that we carefully account for both observed and unobserved heterogeneity. In particular, the apparent 
deterioration in wives' mental health following their husbands' job loss disappears once we use a fixed effects specification to control for time-invariant unobserved heterogeneity. The same holds true when we consider the impact of mothers' involuntary job loss on their adolescent children's mental health. Thus, previous studies which fail to account for the unobserved factors leading to unemployment are likely to be overstating the spillover effects of job loss on mental health.

Second, the fact that we find no evidence for spillover effects in the aggregate does not imply that they are unimportant. On the contrary, involuntary job loss does impose substantial indirect mental health costs on vulnerable families, i.e., those in which job losers do not regain employment quickly or in which financial or relationship stress were already present. Importantly, the mental health burden in these situations, which is substantial, falls much more heavily on women and adolescent girls. Estimates of the overall mental health costs associated with job loss need to account for these indirect effects. Moreover, policies designed to support mental health following job loss need to be family-oriented and targeted towards vulnerable families as well as women and adolescent girls.

\section{Endnotes}

${ }^{1}$ These results are briefly discussed in Section 5 . Full results are available in Additional file 1.

${ }^{2}$ Nevertheless, the question of causality is still far from settled, with recent studies reporting findings that are more mixed (cf., Eliason and Storrie 2009; Salm 2009; Schmitz 2011; Gathergood 2013).

${ }^{3}$ On average, approximately $90 \%$ of all HILDA survey respondents return a completed SCQ for each wave.

${ }^{4}$ One thousand eight hundred thirty-two couples separated during the sample period, 62 of which did so following job loss. Given HILDA's following rules, we are able to retain 671 couples (39 of which experienced job loss) in the year following separation.

${ }^{5}$ We observe 934 cases of adolescents leaving home during the panel, 29 of whom did so in the year following their parents' job loss. We are able to retain 662 of these home leavers in the sample, 23 of whom first began to live separately in the year following parental job loss.

${ }^{6}$ The exception to this is persons that do not respond at every wave. However, inclusion in our main specification of a dummy variable identifying cases where the previous interview was not conducted at the preceding survey wave suggests any bias from this source is trivial-the estimated coefficient was both very small and statistically insignificant.

${ }^{7}$ Comparable data from these financial stress questions are not available for wave 10 , resulting in the additional loss of observations in models that include these variables.

${ }^{8}$ Small sample sizes $(n=11)$ prevent us from evaluating the differential impact of partners unexpected involuntary job loss in couples that are and are not financially stressed.

${ }^{9}$ This necessitates dropping wave 2 as well as wave 1 observations. 


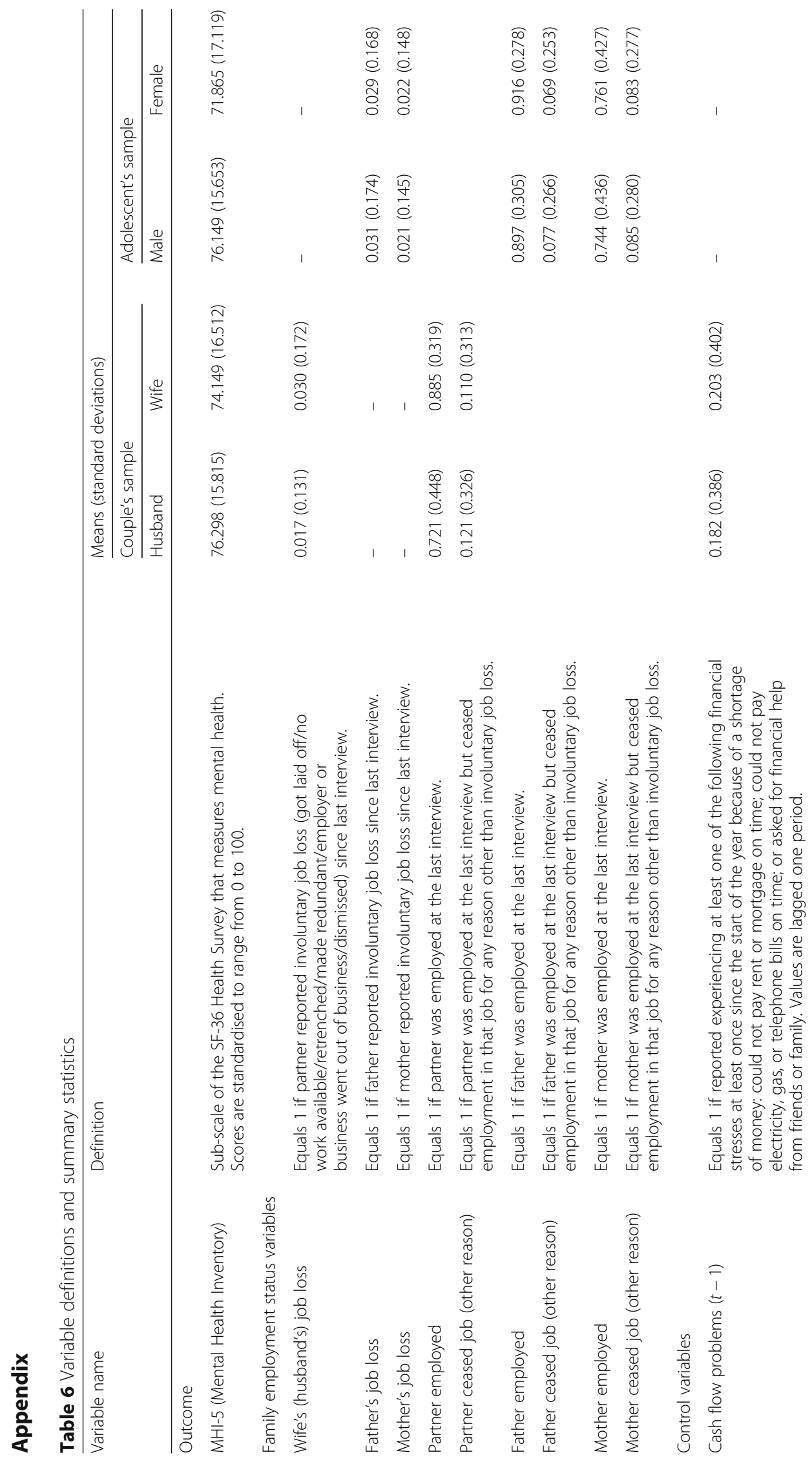




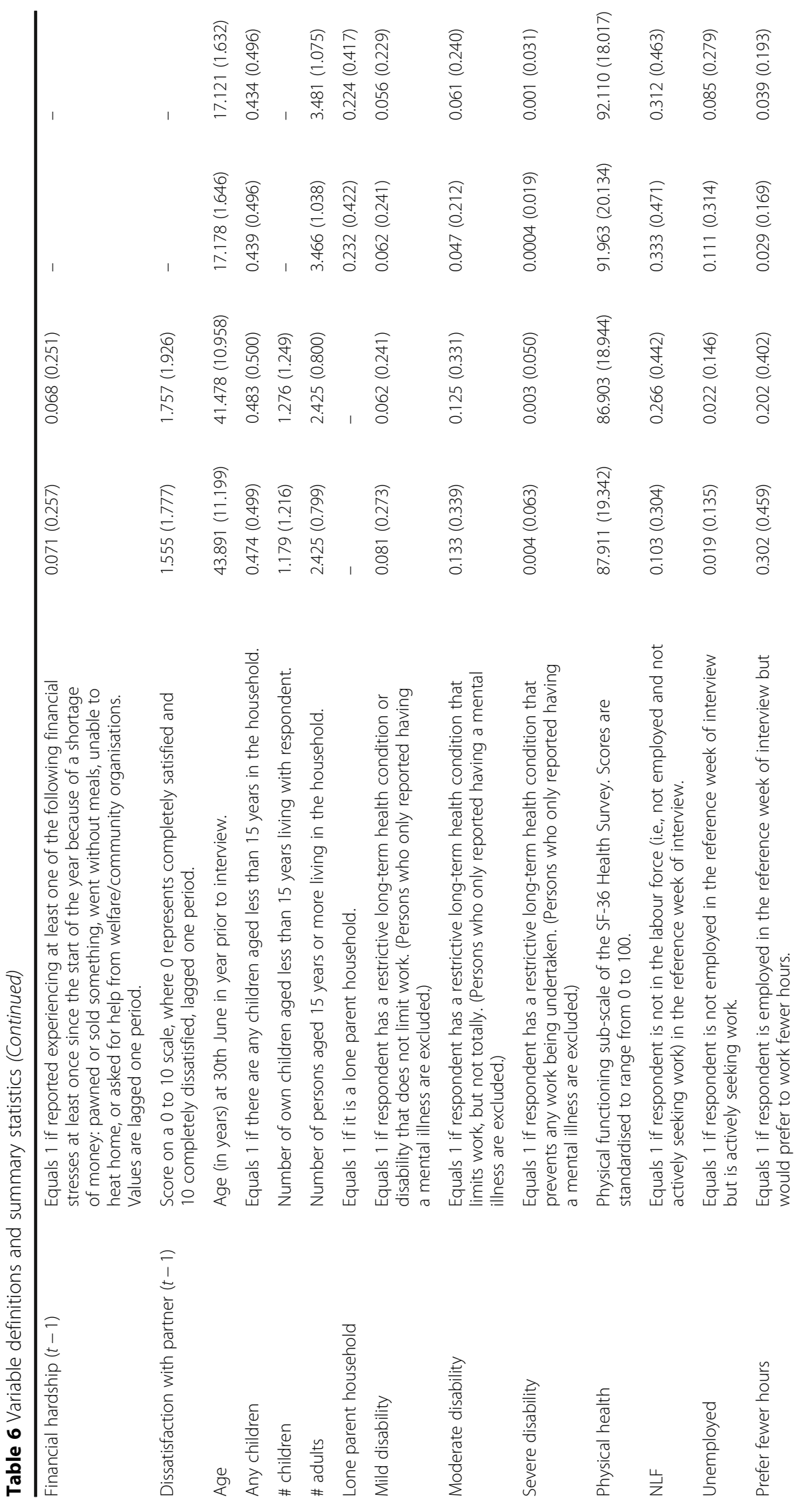




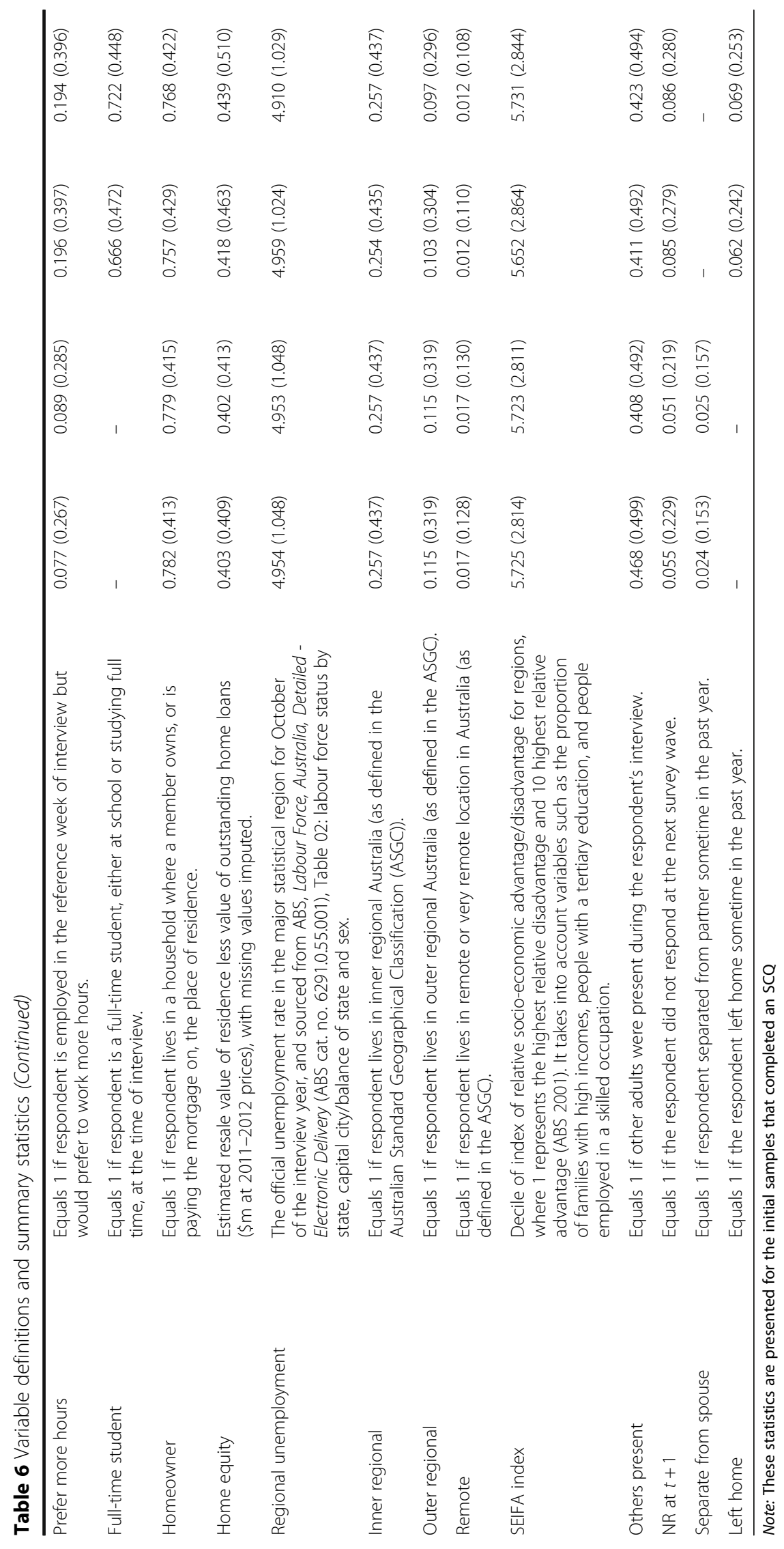




\section{Additional file}

Additional file 1: Results for robustness checks. (DOCX $111 \mathrm{~kb})$

\section{Acknowledgements}

This paper uses confidentialised unit-record file data from the HILDA Survey. The HILDA Survey Project was initiated and is funded by the Australian Government Department of Social Services (DSS) and is managed by the Melbourne Institute of Applied Economic and Social Research, University of Melbourne. The authors also thank the two anonymous referees and the editor for the comments and advice. The findings and views reported in this paper, however, are those of the authors and should not be attributed to either the DSS or the Melbourne Institute. All data were extracted using the PanelWhiz software programme.

Responsible editor: Joni Hersch

\section{Funding}

This research was supported by an Australian Research Council Discovery grant (DP140102614).

\section{Availability of data and materials}

The HILDA Survey data used in this paper are available to bona fide researchers under a licence provided by the Australian Government. Details of how to obtain the data can be found at http://melbourneinstitute.unimelb.edu.au/hilda/for-datausers/ordering-hildasurvey-data

\section{Competing interests}

The IZA Journal of Labor Economics is committed to the IZA Guiding Principles of Research Integrity. The authors declare that they have observed these principles.

\section{Publisher's Note}

Springer Nature remains neutral with regard to jurisdictional claims in published maps and institutional affiliations.

\section{Author details}

${ }^{1}$ Melbourne Institute of Applied Economic and Social Research, University of Melbourne, L5 FBE Bldg, 111 Barry St, Melbourne, Victoria 3010, Australia. ${ }^{2}$ School of Economics, University of Sydney, Room 370, L3 Merewether Bldg, Sydney, NSW 2006, Australia. ${ }^{3}$ ARC Centre of Excellence for Children and Families over the Life Course, University of Queensland, Sydney, Australia. Institute of Labor Economics (IZA), Melbourne, Australia.

Received: 18 January 2017 Accepted: 13 April 2017

Published online: 11 May 2017

\section{References}

Allison BN (2000) Parent-adolescent conflict in early adolescence: research and implications for middle school programs. J Fam Consum Sci Educ 18(2):53-59

Atkinson T, Liem R, Liem JH (1986) The social costs of unemployment: implications for social support. J Health Soc Behav 27(4):317-331

Australian Bureau of Statistics [ABS] (2001) Census of population and housing: Socio-Economic Indexes for Areas (SEIFA), Australia (ABS cat. no. 2033.0.30.001). ABS, Canberra.

Bacikova-Sleskova M, Benka J, Orosova O (2015) Parental employment status and adolescents' health: the role of financial situation, parent-adolescent relationship and adolescents' resilience. Psychol Health 30(4):400-422

Becker GS (1981) A treatise on the family. Harvard University Press, Cambridge

Belle D (1987) Gender differences in the social moderators of stress. In: Barnett RC, Biener L, Baruch GK (eds) Gender and stress. Free Press, New York, pp 257-277

Bertrand M, Kamenica E, Pan J (2015) Gender identity and relative income within households. O J Econ 130(2):571-614

Blau FD, Winkler AE, Ferber MA (2014) The economics of women, men and work, 7th edn. Prentice-Hall, Boston

Bouma E, Ormel J, Verhulst FC, Oldehinkel AJ (2008) Stressful life events and depressive problems in early adolescent boys and girls: the influence of parental depression, temperament and family environment. J Affect Disord 105(1):185-193

Bray JR (2013) Reflections on the evolution of the minimum wage in Australia: options for the future. Australian National University, Canberra, Crawford School SPI Working Paper No. 01/2013

Brody LR (1993) On understanding gender differences in the expression of emotion. In: Ablon SL, Brown DP, Khantzian EJ, Mack JE (eds) Human feelings: explorations in affect development and meaning. The Analytic Press, Hillsdale, pp 87-121

Broman CL, Hamilton VL, Hoffman WS (1990) Unemployment and its effects on families: evidence from a plant closing study. Am J Commun Psychol 18(5):643-659

Chan S, Stevens A (2004) How does job loss affect the timing of retirement? Contrib Econ Anal Policy 3(1):Article 5

Charles KK, Stephens M Jr (2004) Job displacement, disability, and divorce. J Labor Econ 22(2):489-522

Chatterji P, Kim D, Lahiri K (2014) Birthweight and academic achievement in childhood. Health Econ 23(9):1013-1035

Clark AE (2003) Unemployment as a social norm: psychological evidence from panel data. J Labor Econ 21(3):323-351

Cobb-Clark DA, Ribar DC (2012) Financial stress, family relationships, and Australian youths' transitions from home and school. Rev Econ Househ 10(4):469-490

Collins WA, Russell G (1991) Mother-child and father-child relationships in middle adolescence: a developmental analysis. Dev Rev 11(2):99-136

Conger R, Elder GH Jr (1994) Families in troubled times: adapting to change in rural America. Aldine de Gruyter, New York

Conger RD, Conger KJ, Elder GH Jr, Lorenz FO, Simons RL, Whitbeck LB (1993) Family economic stress and adjustment of early adolescent girls. Dev Psychol 29(2):206-219

Cottini E, Lucifora C (2013) Mental health and working conditions in European countries. Ind Labor Relat Rev 66(4):958-988 
Cross SE, Madson L (1997) Models of the self: self-construals and gender. Psychol Bull 122(1):5-37

Cuijpers P, Smits N, Donjker T, Ten Have M, de Graaf R (2009) Screening for mood and anxiety disorders with the fiveitem, the three-item, and the two-item mental health inventory. Psychiat Res 168(3):250-255

Doiron D, Mendolia S (2012) The impact of job loss on family dissolution. J Popul Econ 25(1):367-398

Dooley D, Fielding J, Levi L (1996) Health and unemployment. Annu Rev Publ Health 17:449-465

Drago R, Black D, Wooden M (2005) Female breadwinner families: their existence, persistence and sources. J Sociol 41(4):343-362

Eibich P (2015) Understanding the effect of retirement on health: mechanisms and heterogeneity. J Health Econ 43:1-12

Eliason M (2012) Lost jobs, broken marriages. J Popul Econ 25(4):1365-1697

Eliason M, Storrie D (2009) Job loss is bad for your health-Swedish evidence on cause-specific hospitalization following involuntary job loss. Soc Sci Med 68(8):1396-1406

Farber HS (1993) The incidence and costs of job loss: 1982-91. BPEA: Microeconomics 1:73-132

Feather NT (1990) The psychological impact of unemployment. Springer-Verlag, Berlin

Fletcher J (2009) All in the family: mental health spillover effects between working spouses. B E J Econ Anal Policy 9: Article 1

Fletcher JM (2013) Adolescent depression and adult labor market outcomes. Southern Econ J 80(1):26-49

Fortin NM (2005) Gender role attitudes and the labour-market outcomes of women across OECD countries. Oxford Rev Econ Pol 21(3):416-438

Fröjd S, Kaltiala-Heino R, Pelkonnen M, von der Pahlen B, Marttunenf M (2009) Significance of family life events in middle adolescence: a survey on Finnish community adolescents. Nord J Psychiat 63(1):78-86

Fujita F, Diener E, Sandvik E (1991) Gender differences in negative affect and well-being: the case for emotional intensity. J Pers Soc Psychol 61(3):427-434

Gathergood J (2013) An instrumental variable approach to unemployment, psychological health and social norm effects. Health Econ 22(6):634-654

Ge X, Lorenz FO, Conger RD, Elder GH Jr, Simons RL (1994) Trajectories of stressful life events and depressive symptoms during adolescence. Dev Psychol 30(4):467-483

Gili M, Roca M, Basu S, McKee M, Stuckler D (2013) The mental health risks of economic crisis in Spain: evidence from primary care centres, 2006 and 2010. Eur J Public Health 23(1):103-108

Gough M, Killewald A (2011) Unemployment in families: the case of housework. J Marriage Fam 73(5):1085-1100

Hansen H-T (2005) Unemployment and marital dissolution. Eur Sociol Rev 21(2):135-148

Hoeymans N, Garssen AA, Wagner GP, Verhaak PFM (2004) Measuring mental health of the Dutch population: a comparison of the GHQ-12 and the MHI-5. Health Qual Life Outcomes 2:Article 23

Howe GW, Levy ML, Caplan RD (2004) Job loss and depressive symptoms in couples: common stressors, stress transmission, or relationship disruption? J Fam Psychol 18(4):639-650

Jacobson L, LaLonde R, Sullivan D (1993) Earnings losses of displaced workers. Am Econ Rev 83(4):685-709

Johnson RC, Kalil A, Dunifon RE (2012) Employment patterns of less-skilled workers: links to children's behavior and academic progress. Demography 49(2):747-772

Kalil A, Ziol-Guest K (2005) Single mothers' employment dynamics and adolescent well-being. Child Dev 76(1):196-211

Kasl SV, Rodriguez E, Lasch KE (1998) The impact of unemployment on health and well-being. In: Dohrenwend BP (ed) Adversity, stress, and psychopathology. Oxford University Press, New York, pp 111-121

Kessler RC, McLeod JD (1984) Sex differences in vulnerability to undesirable life events. Am Sociol Rev 49(5):620-631

Kessler RC, McLeod JD, Wethington E (1985) The costs of caring: a perspective on the relationship between sex and psychological distress. In: Sarason IG, Sarason BR (eds) Social support: theory, research and applications. Martinus Nijhoff Publishers, Dordrecht, pp 491-506

Kim J-S, Frees EW (2006) Omitted variables in multilevel models. Psychometrika 71(4):659-690

Kind M, Haisken-DeNew JP (2012) Unexpected victims: how parents' unemployment affects their children's life satisfaction, Melbourne Institute Working Paper Series no. 2/12. Melbourne Institute of Applied Economic and Social Research, University of Melbourne, Melbourne

Komarovsky M (1940) The unemployed man and his family — the effect of unemployment upon the status of the man in fifty-nine families. Dryden, New York

Kuhn A, Lalive R, Zweimüller J (2009) The public health costs of job loss. J Health Econ 28(6):1099-1115

Larson R, Richards MH (1994) Divergent realities: the emotional lives of mothers, fathers, and adolescents. Basic Books, New York

Laursen B (1995) Conflict and social interaction in adolescent relationships. J Res Adolescence 5(1):55-70

Layard R (2013) Mental health: the new frontier for labour economics. IZA J Labor Pol 2:Article 2

Lundberg SJ, Pollak RA, Wales TJ (1997) Do husbands and wives pool their resources? Evidence from the United Kingdom child benefit. J Hum Resour 32(3):463-480

Marcus J (2013) The effect of unemployment on the mental health of spouses-evidence from plant closures in Germany. J Health Econ 32(3):546-558

McCabe CJ, Thomas KJ, Brazier JE, Coleman P (1996) Measuring the mental health status of a population: a comparison of the GHQ-12 and the SF-36 (MHI-5). Brit J Psychiat 169(4):517-521

McMunn AM, Nazroo JY, Marmot MG, Boreham R, Goodman R (2001) Children's emotional and behavioural well-being and the family environment: findings from the health survey for England. Soc Sci Med 53(4): $424-440$

Melnychuk M (2012) Mental health and economic conditions: how do economic fluctuations influence mental problems? Ivie Working Paper Series WP-AD 2012-08. Instituto Valenciano de Investigaciones Económicas, Valencia

Mendolia S (2014) The impact of husband's job loss on partners' mental health. Rev Econ Househ 12(2):277-294

Mervin MC, Frijters P (2014) Is shared misery double misery? Soc Sci Med 107:68-77

Montemayor R, Eberly M, Flannery DJ (1993) Effects of pubertal status and conversation topic on parent and adolescent affective expression. J Early Adolescence 13(4):431-447 
Mossialos E, Wenzl M, Osborn R, Anderson C (2016) 2015 international profiles of health care systems. The Commonwealth Fund, New York

Nock SL (1998) Marriage in men's lives. Oxford University Press, New York

OECD (2012) Sick on the job? Myths and realities about mental health and work. OECD Publishing, Paris

OECD (2014) Making mental health count: the social and economic costs of neglecting mental health care. OECD Publishing, Paris

Östberg V, Alfven G, Hjern A (2006) Living conditions and psychosomatic complaints in Swedish schoolchildren. Acta Paediatr 95(8):929-934

Paikoff RL, Brooks-Gunn J (1990) Physiological processes: what role do they play during the transition to adolescence? In: Montemayor R, Adams GR (eds) From childhood to adolescence: a transitional period? Sage, Newbury Park, pp 63-81

Paul Kl, Moser K (2009) Unemployment impairs mental health: meta-analyses. J Vocat Behav 74(3):264-282

Piko BF, Fitzpatrick KM (2007) Socioeconomic status, psychosocial health and health behaviours among Hungarian adolescents. Eur J Public Health 17(4):353-360

Powdthavee N, Vernoit J (2013) Parental unemployment and children's happiness: a longitudinal study of young people's wellbeing in unemployed households. Labour Econ 24:253-263

Raley SB, Mattingly MJ, Bianchi SM (2006) How dual are dual income couples? Documenting change from 1970 to 2001. J Marriage Fam 68(1):11-28

Rohrbaugh MJ, Cranford JA, Shoham V, Nicklas JM, Sonnega JS, Coyne JC (2002) Couples coping with congestive heart failure: role and gender differences in psychological distress. J Fam Psychol 16(1):3-13

Salm M (2009) Does job loss cause ill health? Health Econ 18(9):1075-1089

Schaller J, Zerpa M (2015) Short-run effects of parental job loss on child heath, NBER Working Paper Series no. 21745. Cambridge, National Bureau of Economic Research

Schmitz H (2011) Why are the unemployed in worse health? The causal effect of unemployment on health. Labour Econ 18(1):71-78

Siegel M, Bradley EH, Gallo WT, Kasl SV (2003) Impact of husbands' involuntary job loss on wives' mental health, among older adults. J Gerontol B Psychol Sci Soc Sci 58B(1):S30-S37

Steinberg L, Silk JS (2002) Parenting adolescents. In: Bornstein MH (ed) Handbook of parenting, vol 1: children and parenting (2nd ed). Lawrence Erlbaum Associates, Mahwah, pp 103-135

Stevens AH (1997) Persistent effects of job displacement: the importance of multiple job losses. J Labor Econ 15(1):165-188 Strand BH, Dalgard OS, Tambs K, Rognerud M (2003) Measuring the mental health status of the Norwegian population: a comparison of the instruments SCL-35, SCL-10, SCL-5 and MHI-5 (SF-36). Nord J Psychiat 57(2):113-118

Ström S (2003) Unemployment and families: a review of research. Soc Serv Rev 77(3):399-430

Sund AM, Larsson B, Wichstrøm L (2003) Psychosocial correlates of depressive symptoms among 12-14-year-old Norwegian adolescents. J Child Psychol Psyc 44(4):588-597

Townsend NW (2002) The package deal: marriage, work, and fatherhood in men's lives. Temple University Press, Philadelphia Verbeek M, Nijman T (1992) Testing for selectivity bias in panel data models. Int Econ Rev 33(3):681-703

Ware JE, Snow KK, Kosinski M, Gandek B (2000) SF-36 health survey: manual and interpretation guide. QualityMetric Inc Lincoln

Watson N, Wooden M (2012) The HILDA survey: a case study in the design and development of a successful household panel survey. Longit Life Course Stud 3(3):369-381

Whiteford P (2010) The Australian tax-transfer system: architecture and outcomes. Econ Rec 86(275):528-544

Wilcox WB, Nock SL (2007) "Her" marriage after the revolutions. Sociol Forum 22(1):103-110

Wooden M, Li N (2014) Panel conditioning and subjective well-being. Soc Indic Res 117(1):235-255

World Bank (2012) World development report 2012: gender equality and development. The World Bank, Washington DC

Yamazaki S, Fukuhara S, Green J (2005) Usefulness of five-item and three-item mental health inventories to screen for depressive symptoms in the general population of Japan. Health Qual Life Outcomes 3:Article 48

Zagorsky JL (2003) Husbands' and wives' view of the family finances. J Socio Econ 32(2):127-146

\section{Submit your manuscript to a SpringerOpen ${ }^{\circ}$ journal and benefit from:}

- Convenient online submission

- Rigorous peer review

- Immediate publication on acceptance

- Open access: articles freely available online

- High visibility within the field

Retaining the copyright to your article

Submit your next manuscript at $\boldsymbol{\sim}$ springeropen.com 